Randomized Controlled Trial

\title{
Consumption of yacon flour improves body composition and intestinal function in overweight adults: A randomized, double-blind, placebo-controlled clinical trial
}

\author{
Adriane M. Machado ${ }^{\text {a, }}{ }^{*}$, Nayara B.M. da Silva ${ }^{\text {b }}$, José Benício P. Chaves ${ }^{\text {b }}$, \\ Rita de Cássia G. Alfenas ${ }^{\text {a }}$
}

${ }^{a}$ Universidade Federal de Viçosa, Departamento de Nutrição e Saúde, Viçosa, MG, Brazil

b Universidade Federal de Viçosa, Departamento de Tecnologia de Alimentos, Viçosa, MG, Brazil

\section{A R T I C L E I N F O}

\section{Article history:}

Received 25 September 2018

Accepted 10 December 2018

\section{Keywords}

Yacon

Fructooligosaccharides

Adiposity

Glycemia

Gastrointestinal function

\section{S U M M A R Y}

Background \& aims: Yacon root is a natural source of fructooligosaccharides (FOS), and it has been studied for its potential effect as a functional food. However, FOS in the in natura root are rapidly hydrolyzed. Thus, the use of dehydrated products such as flour ensures stability of FOS. The effect of chronic consumption of yacon flour on body composition, food intake and of biochemical variables concentration has not yet been evaluated in humans. Thus, we evaluated the effects of yacon flour consumption on these variables associated with excess body weight.

Methods: Twenty-six adults ( $31.3 \pm 8.5$ years) with excess weight $\left(30.4 \pm 2.4 \mathrm{~kg} / \mathrm{m}^{2}, 40.16 \pm 6.7 \%\right.$ body fat) participated in this randomized, double-blind, six-week study. Subjects were randomly allocated to one of the experimental groups (control $(n=13)$ or yacon flour $(n=13)$ ), received the prescription of energy-restricted diets (- $500 \mathrm{kcal} / \mathrm{day}$ ) and daily consumed a breakfast drink not containing or containing $25 \mathrm{~g}$ of yacon flour ( $0.1 \mathrm{~g}$ of FOS $/ \mathrm{kg}$ body weight). At the beginning and at the end of the study, biochemical analyses (glycemia, insulinemia, lipid profile and liver function markers), anthropometrics (weight, waist, hip and neck circumference and sagittal abdominal diameter), body composition (lean mass, total body fat, trunk fat, android fat and gynoid fat), blood pressure, intestinal function, and food intake were assessed.

Results: Daily yacon flour consumption was well tolerated, did not cause adverse gastrointestinal effects, increased dietary fiber consumption, promoted greater body weight, waist circumference, waist to height index, sagittal abdominal diameter, and body fat reduction, besides improving bowel function in comparison to the control group.

Conclusions: Yacon flour served as a natural fiber supplement and proved to be an effective adjuvant to be used in nutritional strategies to control excess body weight.

(C) 2018 European Society for Clinical Nutrition and Metabolism. Published by Elsevier Ltd. All rights reserved.

\section{Introduction}

Nearly two billion adults around the world are overweight. Of these, over 650 million are obese. Excess of body weight is directly associated with an increase in the prevalence of diseases, such as type 2 diabetes, hypertension, cardiovascular diseases and cancer [1]. Excessive fat and sugar consumption and low dietary fiber

\footnotetext{
* Corresponding author. Departamento de Nutrição e Saúde, Universidade Federal de Viçosa, Avenida PH Rolfs, s/n, Viçosa, Minas Gerais, CEP 36570-000 Brazil.

E-mail address: adrianemoreiramachado@gmail.com (A.M. Machado).
}

consumption, combined with physical inactivity have contributed to the increasing prevalence of excess weight. On the other hand, the consumption of foods rich in fibers and of low caloric value that can help reduce food intake and thus can lower body weight is an interesting strategy to prevent/control this pathology.

In this sense, the yacon (Smallanthus sonchifolius) tuberous root originating in the Andes region, has been gaining prominence in the scientific environment. That root has a low caloric value, since it contains more than $70 \%$ of water and it is rich in dietary fiber (approximately $45 \mathrm{~g}$ in $100 \mathrm{~g}$ dry matter), mainly fructooligosaccharides (FOS) [2]. Due to the naturally high 
concentrations of FOS, yacon root has been extensively studied for its potential as a functional food [2]. However, soon after yacon harvesting, FOS hydrolysis and increase in the amount of free sugars occur. On the other hand, dehydrated products of that root, such as flour, guarantees the existence of a natural product with great FOS stability [3]. Additionally, the consumption of flour allows the ingestion of a greater amount of FOS in a smaller portion of food, when compared to the root in natura.

Few studies have evaluated the functional effects of yacon flour in humans [4,5]. The effect of chronic flour consumption on body composition, food intake and biochemical variables concentrations has not yet been assessed in humans yet. However, yacon supplementation in the lyophilized form, in extract or syrup, exerted positive effects on body weight [6], blood lipid profile [6], glycemic response [6-8], and intestinal function [6,8,9]. Additionally, fructans, present in large quantities in yacon, stimulate the secretion of endogenous intestinal peptides, favoring the reduction of food intake and the beneficial modulation of the intestinal microbiota [10].

The benefits highlighted above suggest that yacon flour consumption may be effective to prevent and treat excess body weight and associated complications. Thus, the objective of the present study was to evaluate the effects of yacon flour consumption on variables associated with excess body weight, such as body composition, anthropometry, food intake, biochemical variables, intestinal function and blood pressure.

\section{Methodology}

\subsection{Chemical composition of yacon flour}

The chemical composition of yacon flour (Linea Verde Alimentos, Curitiba, Brazil) was determined using official methods of analysis of Association of Official Analytical Chemists (AOAC) [11]. Total carbohydrate content was calculated by difference, subtracting from 100 the sum of the values obtained for moisture, protein, fat and ashes. Dietary fiber content was obtained from AOAC enzymatic-gravimetric method, using Total Dietary Fiber Assay Kit (Sigma-Aldrich ${ }^{\circledR}$ ). FOS content was determined according to the methodology described by Pedreschi et al. [12] with some modifications. Total dietary fiber was determined adding the obtained dietary fiber plus FOS contents.

FOS determination was based on quantification of glucose, fructose, and sucrose present in the sample before and after enzymatic hydrolysis of FOS. Sugars were measured by highperformance anion-exchange chromatography with pulsed amperometric detection (HPAEC-PAD) (Metrohm, Herisau, Switzerland) through a column Metrosep Carb 1 (dimensions $150 \times 4.0 \mathrm{~mm})($ Metrohm, Herisau, Switzerland). The mobile phase used was $\mathrm{NaOH} 0.2 \mathrm{~mol} \mathrm{~L}-1$, a flow rate of $0.5 \mathrm{~mL}$ min-1 and temperature $30^{\circ} \mathrm{C}$ column. To determine the initial amounts of sugars, the yacon flour was diluted $(0.3 \mathrm{~g}$ of flour in $30 \mathrm{~mL}$ of ultrapure water) and centrifuged at $7000 \mathrm{~g}$ for $20 \mathrm{~min}$. Before injection into the chromatograph, $300 \mu \mathrm{L}$ of the supernatant were removed and diluted in $10 \mathrm{~mL}$ of ultrapure water. For enzymatic hydrolysis, $100 \mu \mathrm{L}$ of the supernatant was removed and mixed with $50 \mu \mathrm{L}$ of the inulinase solution (Megazyme, County Wicklow, Ireland) in $50 \mathrm{mM}$ acetate buffer, $\mathrm{pH}$ 4.5. The mixture was incubated in a $40{ }^{\circ} \mathrm{C}$ water bath $\mathrm{C}$ for $30 \mathrm{~min}$. The sugars were identified and quantified by comparing the retention times of previously analyzed standards. The concentration of FOS was calculated according to Prosky \& Hoebregs [13] and Pedreschi et al., [12]. The results were expressed as g fructans per $100 \mathrm{~g}$ of flour.

\subsection{Subjects}

Subjects were initially recruited through local advertisements, from August 2017 to May 2018. Subjects were adult men and women (31.3 \pm 8.5 years old), with excess body weight $\left(30.4 \pm 2.4 \mathrm{~kg} / \mathrm{m}^{\frac{1}{2}}, 40.16 \pm 6.7 \%\right.$ body fat $)$, who regularly consumed breakfast, had low physical activity level and dietary restraint $\leq 14$. Smokers, pregnant/lactating women, and people with: habitual alcohol consumption greater than $30 \mathrm{~g} /$ day; use of medications that affect glycemia or energy metabolism; use of medications, herbs or diets to reduce appetite and body weight; had a body weight gain or loss of at least $5 \mathrm{~kg}$ in the 3 months prior to the beginning of the study; recent change in the level of physical activity; aversion or intolerance to the food provided in the study; existence or history of endocrine, cardiovascular, arterial hypertension, liver and/or gastrointestinal diseases; report of eating disorders; use of laxatives or antibiotics in the three months prior to the start of the study; use of probiotics, prebiotics or symbiotics ( $>2$ times per week) in the month prior to the start of the study, and women with menstrual irregularity (three months prior to the beginning of the study) were not included in the study.

Subjects were informed about the objectives of the study and signed a consent form before being included in the study. The protocol of the present study was approved by the Universidade Federal de Viçosa Ethics Committee (Process no.1,875,372/CAAE no. 62047316.6.0000.5153) and was conducted in accordance with the Declaration of Helsinki. The trial is registered in the Brazilian Registry of Clinical Trials (ReBEC) http://www.ensaiosclinicos.gov. br/(identifier: RBR-6YH6BQ).

\subsection{Experimental protocol}

In this is double-blind, parallel, randomized, placebo-controlled clinical trial study with a duration of six weeks ( \pm 5 days), the volunteers were randomly allocated to the control group or the yacon flour group. We adopted a tolerance of \pm 5 days to the end the women's trial, to ensure that anthropometry/body composition were not assessed in the menstrual period.

All participants were allocated $(1: 1)$ to receive either yacon flour or placebo (control). Block randomization technique (with block size equal to 4) was used to allocate the subjects into the groups. This technique was applied by a person who was not part of the research group.

During the intervention period, energy-restricted diets ($500 \mathrm{kcal} /$ day) were prescribed and subjects daily consumed $350 \mathrm{~mL}$ of a control drink without the addition of yacon flour (CON) or a test drink (YAC) containing yacon flour at breakfast. The other meals of the day were consumed in free living conditions.

Food intake, body composition (total body fat and specific regions (trunk, android and gynoid) and total lean mass), anthropometry (weight, waist, hip, thigh and neck circumferences and sagittal abdominal diameter), blood pressure, biochemical evaluation (glycemia, insulin, lipid profile and markers of liver function), stool consistency, gastrointestinal symptoms, and fecal $\mathrm{pH}$ were assessed before the beginning, and at the end of the study. Subjects were instructed to maintain their level of physical activity constant throughout the study, and were also instructed not to engage in strenuous physical activity within $24 \mathrm{~h}$ prior to the biochemical assessments.

One week before beginning the study, subjects were instructed not to consume alcoholic beverages and not to alter their usual food intake. A standard dinner consisting of $200 \mathrm{ml}$ of Tial ${ }^{\circledR}$ nectar (grape flavor), $85 \mathrm{~g}$ of pasta and $10 \mathrm{~g}$ of Parmesan cheese $(523 \mathrm{kcal}$, 57.4\% CHO, 10.3\% PTN, 32.3\% LIP, $2.1 \mathrm{~g}$ fibers) was supplied to be consumed the night before the assessments (Suppl. Material 1). 


\subsection{Breakfast}

The amount of yacon flour (25 g/day, providing $0.1 \mathrm{~g} \mathrm{FOS} / \mathrm{kg}$ body weight/day) added to the YAC group drink was determined based on other studies and previous laboratory tests to avoid possible undesirable gastrointestinal effects due to excessive yacon flour ingestion $[6,8]$. Once purchased, the yacon flour was stored at $21^{\circ} \mathrm{C}$ and $64 \%$ humidity until the moment of use.

Corn starch was added to CON drink so that it presented similar energy and macronutrient contents as the YAC drink (Table 1). The drinks' nutritional composition was based on the nutritional information contained in the food labels and on the nutritional composition analysis of yacon flour (Table 2). Seven flavors of drinks (cappuccino, cocoa milk, coffee with milk, guava, mango, blackberry and passion fruit vitamins), presenting similar nutritional composition, were served to avoid monotony and increase adherence to the study protocol.

The volunteers daily attended the Laboratory of Food Intake, Department of Nutrition and Health, Federal University of Viçosa Brazil, from Monday to Friday to consume breakfast. On weekends, identical drinks were provided to be consumed at home. Subjects were requested to bring to the laboratory any quantities of food supplied but not ingested on weekends. In addition, adherence to the protocol on weekends was verified by asking the subjects about the consumption of the breakfast provided. A trained investigator, not involved on data collection and analyses, was responsible for assessing adherence to the protocol, preparing and serving the drinks. Drinks were served in colored cups to avoid visual identification of the type of drink tested. There was no description or dietary information on these cups.

\subsection{Prescribed diets}

Energy-restricted diets were prescribed (-500 kcal/day) [14] which were calculated considering the level of physical activity, the estimated energy requirement (Estimated Energy Requirement EER) for each subject and the nutritional value of the daily drinks consumed. The diets prescribed to the experimental groups

Table 1

Mean \pm SD nutritional composition of the seven rotating breakfast drinks ${ }^{1}$ tested.

\begin{tabular}{|c|c|c|}
\hline Nutritional composition & Control breakfast & Yacon flour breakfast \\
\hline Energy (kcal) & $418 \pm 21.6$ & $437 \pm 23.9$ \\
\hline Carbohydrate (g) & $60.23 \pm 5.18$ & $63.14 \pm 5.09$ \\
\hline Protein $(\mathrm{g})$ & $14.15 \pm 1.3$ & $14.85 \pm 1.3$ \\
\hline Total fat (g) & $13.38 \pm 0.49$ & $13.94 \pm 0.41$ \\
\hline Dietary fiber ${ }^{2}(\mathrm{~g})$ & $2.63 \pm 3.91^{\mathrm{a}}$ & $13.72 \pm 3.97^{\mathrm{b}}$ \\
\hline FOS (g) & - & 8.69 \\
\hline
\end{tabular}

${ }^{1}$ Based on the information contained in the food labels of the ingredients added to prepare the drinks, and on the nutritional composition analysis of yacon flour determined by the researchers (Table 2). ${ }^{2}$ Dietary fiber: soluble fiber (kit) + insoluble fiber (kit) + FOS. Means followed by distinct letters, in the same line, indicate inter-groups difference by Student's $t$ test or Mann-Whitney U signed-rank test, $\mathrm{p}<0.05$. FOS: fructooligosaccharides.

Table 2

Chemical characterization of the yacon flour used to prepare the breakfast drinks.

\begin{tabular}{ll}
\hline Nutrients & Content $(\mathrm{g} / 100 \mathrm{~g}$ flour $)$ \\
\hline Carbohydrate $^{1}(\mathrm{~g})$ & 85.5 \\
Protein $(\mathrm{g})^{\text {Total fat }(\mathrm{g})}$ & 2.8 \\
Fiber $^{2}(\mathrm{~g})$ & 0.9 \\
FOS $(\mathrm{g})$ & 46.9 \\
\hline
\end{tabular}

${ }^{1}$ Carbohydrate: $100-$ (protein + fat + ashes + moisture). ${ }^{2}$ Fiber: soluble fiber

(kit) + insoluble fiber (kit) + FOS. FOS: fructooligosaccharides. presented similar energy density, and macronutrients distribution $(1734 \pm 494.2 \mathrm{kcal} v s .1729 \pm 471.1 \mathrm{kcal}$, carbohydrate: $51.6 \pm 3.6 \% \mathrm{E}$ vs. $51.3 \pm 2.4 \%$ E, protein: $21.2 \pm 2.4 \%$ E vs. $21.0 \pm 1.9 \%$ E, fat: $28.8 \pm 2.4 \%$ E vs. $29.1 \pm 2.0 \% \mathrm{E}$, for CON and YAC, respectively).

\subsection{Dietary assessments}

Food intake on the week before baseline, and during the experimental period, was assessed using three non-consecutive days ( 2 week days and 1 weekend day) 24-h food records. Each dietary record was review with the subjects to ensure accuracy and completeness. Macronutrients and dietary fiber intakes were analysed by a two dietitians and the results of these analyses were checked by a third dietitian, using DietPro software (version $5.2 \mathrm{i}$, Agromídia, MG, Brazil).

\subsection{Anthropometric, body composition, and blood pressure measurements}

Body weight was measured on a digital platform scale with a resolution of $50 \mathrm{~g}$ (Toledo $\AA$, Model 2096PP/2, SP, Brazil), while subjects were barefoot and wearing lightweight clothing. Height was measured to the nearest $0.1 \mathrm{~cm}$ using a wall-mounted stadiometer (Wiso, Chapecó, SC, Brazil). BMI was calculated by dividing body $(\mathrm{kg})$ by height $(\mathrm{m})$ squared. Waist circumference and sagittal abdominal diameter were measured in the midpoint between the last rib and iliac crest. Hip, thigh and neck circumferences were also measured. All variables were measured in triplicate and the average of the two nearest values of the three collected measurements was recorded. Waist/heigh, waist/hip, and conicity index (CI) were calculated following the formula: $\mathrm{CI}=$ [waist circumference $(\mathrm{m})]$ / $[0.109 \sqrt{ }($ body weight $(\mathrm{kg}) /$ height $(\mathrm{m}))]$. Blood pressure was assessed using an automatic Omron HEM-7200 device (Omron Inc., Dalian, China) in both arms [15].

Dual-energy X-ray absorptiometry scan (DXA) (model Prodigy Advance, GE Healthcare Inc., Waukesha, WI) was performed to assess changes in body composition according to manufacturer's instructions. Values of lean mass, total body fat, and fat distribution (truncal, gynoid, and android regions) were obtained. Anthropometric and blood pressure measurements were assessed by a single investigator.

\subsection{Categorization of bowel movements and evaluation of gastrointestinal symptoms}

The Bristol scale was used to categorize bowel movements. This scale descriptively evaluates the shape and consistency of stools [16]. Gastrointestinal symptoms presented during the study were evaluated using a gastrointestinal symptom assessment scale (GSRS) translated and validated for the Brazilian population [17].

\subsection{Biochemical evaluation}

Antecubital blood samples were collected after $12 \mathrm{~h}$ of fasting. Samples were then centrifuged for serum and plasma separation (3500 rpm, $4{ }^{\circ} \mathrm{C}, 15 \mathrm{~min}$ ), and immediately frozen at $-80^{\circ} \mathrm{C}$ until analysis. Glucose, triglycerides, total cholesterol, high density lipoprotein cholesterol (HDL-c), aspartate amino transferase (AST) and alanine aminotransferase (ALT) concentrations were quantified by an automated analyzer system (BS-200 ${ }^{\mathrm{TM}}$ Chemistry Analyzer, Mindray) using commercially available colorimetric assay kits (K802, K117, K083, K071, K048 and K049, respectively; Bioclin ${ }^{\circledR}$, MG, Brazil). Low density lipoprotein (LDL-c) concentration was calculated following the formula: LDL-c = total cholesterol - HDL-c - (triglycerides/5). Creactive protein (CRP) was assessed by the quantitative method 
based on immunoturbidimetric, using commercially available kit for ultrasensitive CRP (Bioclin ${ }^{\circledR}$ MG, Brazil). Insulin was determined by chemiluminescent immunoassay (Access Ultrasensitive Insulin). The Homeostasis Model Assessment index (HOMA-IR) was calculated and insulin resistance was identified according to the cutoff point established by Geloneze \& Tambascia [18]. The atherogenic index (TG/HDL-c ratio) [19] was also calculated.

\subsection{Statistical analysis}

The present study had a statistical power of 95\% [20] to detect a $7 \%$ reduction in the subjects' body fat, considering their baseline mean and standard deviation values. Body fat and body weight were measured as a primary outcome, whilst other anthropometrics and body composition variables, glycemic parameters, lipid profile, liver function markers, blood pressure, intestinal function, and food intake were measured as secondary outcomes.

Data was entered by two independent researchers to ensure reliability and accuracy. Statistical analyses were conducted using SPSS software (SPSS Inc., Chicago, IL, 2015, version 22.0.0.0). Delta $(\Delta)$ was calculated subtracting the baseline value from the final value obtained. Data normality and homoscedasticity were evaluated by the Shapiro-Wilk and Levene tests, respectively. The nutritional composition of the breakfast drinks tested and the description of the sample data at baseline were compare through Student's $t$ test or Mann-Whitney U signed-rank test. The effect of the intervention was assessed by comparing the outcome variables intra and inter CON and YAC groups using generalized estimating equation model (GEE). For the variables with normal distribution, a connection identify function was used. For the variables that did not follow normal distribution, gamma distribution with log link was used. The working correlation matrix used was unstructured and robust estimator covariance matrix. $\mathrm{CON}$ group was chosen as reference. Unstandardized Coefficients of the interaction term between time and the group, and the associated confidence interval (95\% CI) were reported. We used a Bonferroni post-hoc to identify the differences on group, time and group*time interaction. These models were adjusted by baseline values. A $\alpha<0.05$ was adopted as the level of statistical significance.

\section{Results}

\subsection{Subjects' characterization}

Four hundred and four potential subjects were assessed for eligibility, but only thirty were selected. Of these, four subjects did not complete the study protocol (Fig. 1). Thus, data from twenty-six subjects was included in the analyses.

Subjects' body composition, food intake and biochemical variables concentrations did not differ the groups at baseline. According to BMI, most (57.7\%) of the subjects were obese, and $42.3 \%$ were overweight. However, according to body fat \%, all subjects were considered obese. The subjects were $31.3 \pm 8.5$ years old, most $(57.7 \%)$ of them were women, and none of them had systolic blood pressure higher than $139 \mathrm{mmHg}$ and diastolic blood pressure higher than $90 \mathrm{mmHg}$ (Table 3). Thirty-eight percent had high cholesterol, 30.7\% high triglycerides and 19.2\% high LDL, according to the Brazilian Society of Cardiology [21]. None of the subjects had blood glucose higher than $5.5 \mathrm{mmol} / \mathrm{L}$. All subjects conducted low level of physical activity.

Two subjects from the YAC group and three from the CON group were considered insulin resistant. However, after removing these subjects from the analyses did not alter the results of the comparisons between groups. Therefore, these subjects were kept in their respective groups and thus, no subject was excluded from the analyses.

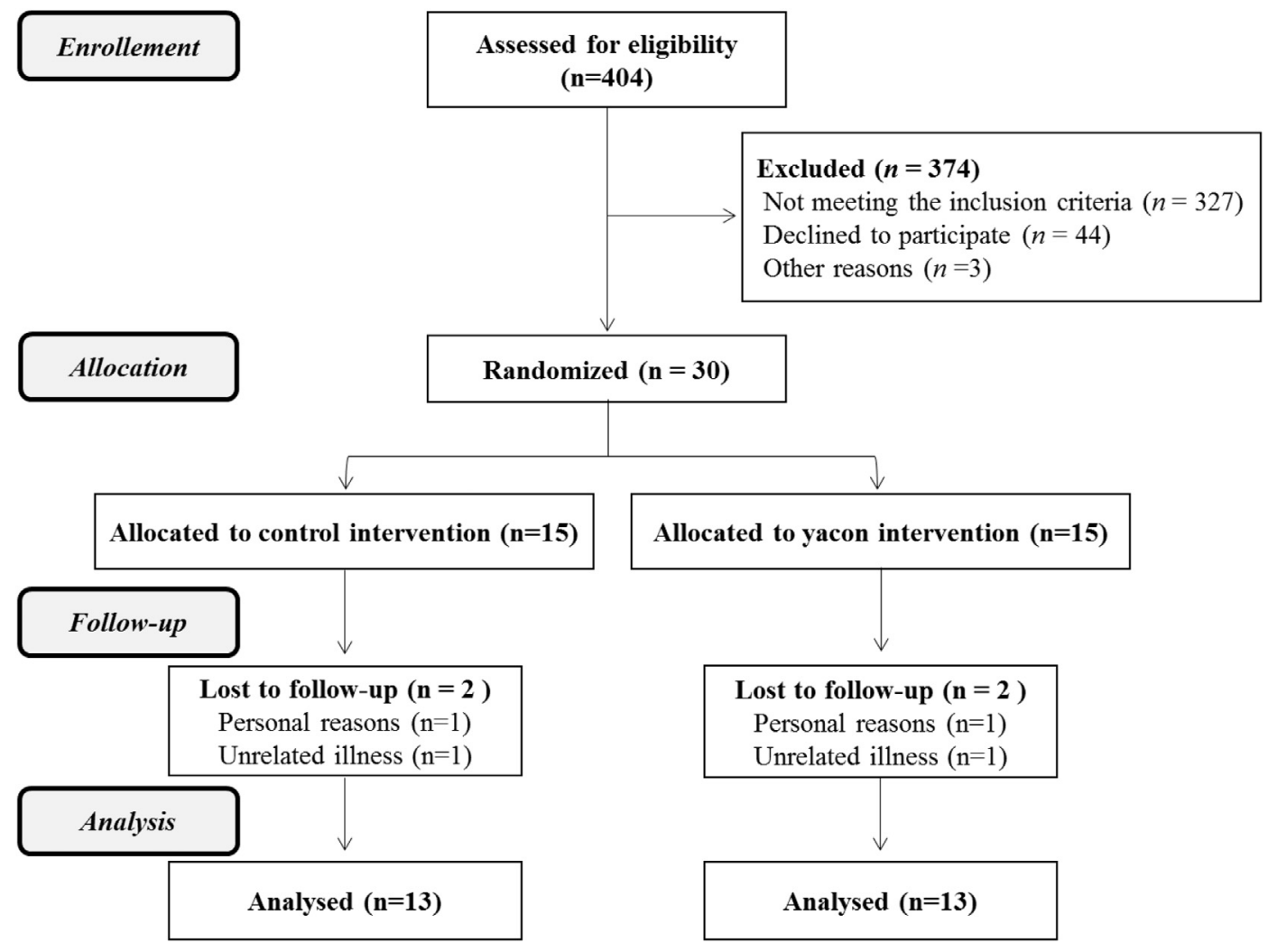

Fig. 1. CONSORT diagram showing the flow of participants through the study. 
Table 3

Mean baseline characteristics of the subjects according to experimental groups.

\begin{tabular}{|c|c|c|}
\hline & $\begin{array}{l}\text { Control group } \\
(\mathrm{n}=13)\end{array}$ & $\begin{array}{l}\text { Yacon flour group } \\
(\mathrm{n}=13)\end{array}$ \\
\hline Men/Women (n) & $6 / 7$ & $5 / 8$ \\
\hline Age (years) & $32.92 \pm 9.68$ & $29.77 \pm 7.26$ \\
\hline Body weight (kg) & $84.93 \pm 13.83$ & $88.52 \pm 15.21$ \\
\hline Body mass index $\left(\mathrm{kg} / \mathrm{m}^{2}\right)$ & $30.08 \pm 2.04$ & $30.80 \pm 2.85$ \\
\hline Waist circumference $(\mathrm{cm})$ & $100.17 \pm 8.18$ & $102.62 \pm 9.37$ \\
\hline Sagittal abdominal diameter $(\mathrm{cm})$ & $19.12 \pm 2.16$ & $18.78 \pm 2.26$ \\
\hline Total body fat (kg) & $32.56 \pm 5.41$ & $36.61 \pm 8.15$ \\
\hline Total lean mass $(\mathrm{kg})^{1}$ & $48.28 \pm 11.87$ & $46.57 \pm 10.00$ \\
\hline Systolic blood pressure (mmHg) & $112.66 \pm 8,43$ & $113.96 \pm 11.03$ \\
\hline Diastolic blood pressure (mmHg) & $67.33 \pm 7,17$ & $69.30 \pm 7.86$ \\
\hline HOMA-IR & $2.11 \pm 0,68$ & $2.11 \pm 0.72$ \\
\hline
\end{tabular}

${ }^{1}$ Non-parametric data. Data are not significantly different by Student's $t$ test or Mann-Whitney U signed-rank test, $\mathrm{p}>0.05$.

\subsection{Food intake}

In both groups, the average daily dietary fiber intake at baseline was below the recommended level (14 $\mathrm{g}$ of fiber/1000 $\mathrm{kcal} /$ day). At the end of six weeks, both groups reached the daily recommendation. However, on YAC group dietary fiber intake was $52 \%$ higher than CON group. Energy, carbohydrate, and fat intakes reduced in both groups (Table 4).

\subsection{Anthropometry and body composition}

Body weight, total body fat, waist-to-height ratio, waist-to-hip ratio, conicity index, sagittal abdominal diameter, besides waist, neck and thigh circumferences reduced in both groups after six weeks of intervention (Table 5). However, at the end of the experimental period, YAC group present lower body weight, gynoid fat, waist circumference, sagittal abdominal diameter and waist/ height index than CON group (Fig. 2). Besides, hip circumference and body fat in specific regions (trunk and android body fat) reduced, and total lean mass increased only in the YAC group (Table 5).

\subsection{Gastrointestinal effect}

YAC subjects had higher frequency of reflux and heartburn episodes at baseline (Table 6). During the first days of intervention, approximately $15 \%$ of the YAC group subjects reported abdominal discomfort symptoms, such as flatulence and abdominal pain. These effects decreased after the second week and no significant difference was observed at the end of the experimental period. YAC group presented lower constipation frequency, and a higher frequency of softened stools at the end of the experimental period compare with CON group (Table 6). Besides, hard stools frequency reduced in the YAC group (Table 6).

\subsection{Biochemical tests}

The concentrations of most of the biochemical variables (glucose, insulin, lipid profile, and liver function markers) assessed in this study did not differ at baseline or after six weeks of intervention between groups (Suppl. Material 2). All YAC group subjects that had dyslipidemia at baseline reduced blood lipid profile concentration, and in $50 \%$ of them, the values reached normality. On the other hand, that reduction was verified in $69 \%$ of the CON group subjects with dyslipidemia, and of those, $40 \%$ reached normality.

Table 4

Dietary assessments at baseline and after the 6-week intervention according to experimental groups.

\begin{tabular}{|c|c|c|c|c|c|}
\hline & \multicolumn{2}{|c|}{ Control $(\mathrm{n}=13)$} & \multicolumn{2}{|c|}{ Yacon flour $(\mathrm{n}=13)$} & \multirow[t]{2}{*}{$\beta^{2}(95 \% \mathrm{CI})$} \\
\hline & Baseline & 6 weeks & Baseline & 6 weeks & \\
\hline Energy (kcal) & $1877 \pm 158.2^{\mathrm{a}}$ & $1552 \pm 109.5^{\mathrm{b}}$ & $2018 \pm 124.5^{\mathrm{a}}$ & $1557 \pm 94.6^{\mathrm{b}}$ & $-135.94(-527.27 ; 255.37)$ \\
\hline Carbohydrate (g) & $239.1 \pm 19.7^{\mathrm{a}}$ & $191.6 \pm 10.9^{\mathrm{b}}$ & $270.1 \pm 22.7^{\mathrm{a}}$ & $188.8 \pm 12.8^{\mathrm{b}}$ & $-33.79(-91.61 ; 24.02)$ \\
\hline Protein $(g)^{1}$ & $70.9 \pm 8.9$ & $77.2 \pm 8.9$ & $75.5 \pm 4.9$ & $77.9 \pm 7.1$ & $-0.05(-0.33 ; 0.22)$ \\
\hline Fat $(\mathrm{g})^{1}$ & $69.5 \pm 8.9^{\mathrm{a}}$ & $53.0 \pm 4.9^{\mathrm{b}}$ & $70.6 \pm 4.2^{\mathrm{a}}$ & $54.5 \pm 3.9^{b}$ & $0.01(-0.25 ; 0.27)$ \\
\hline Dietary Fiber (g) & $17.2 \pm 1.4^{\mathrm{a}, \mathrm{A}}$ & $25.5 \pm 1.4^{\mathrm{b}, \mathrm{A}}$ & $24.9 \pm 2.3^{\mathrm{a}, \mathrm{B}}$ & $38.8 \pm 1.9^{\mathrm{b}, \mathrm{B}}$ & $5.59(0.51 ; 11.69)$ \\
\hline
\end{tabular}

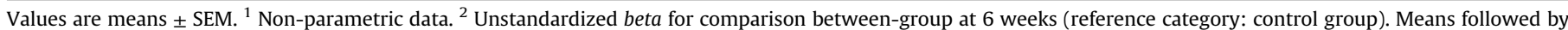

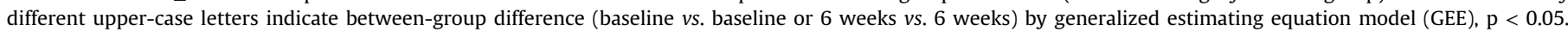

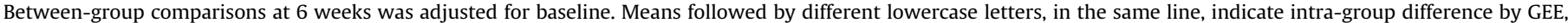
$\mathrm{p}<0.05$.

Table 5

Anthropometric, body composition and blood pressure at baseline and after the 6-week intervention according to experimental groups.

\begin{tabular}{|c|c|c|c|c|c|}
\hline & \multicolumn{3}{|c|}{ Control $(n=13)$} & Yacon flour $(\mathrm{n}=13)$ & \multirow[t]{2}{*}{$\beta^{2}(95 \% \mathrm{CI})$} \\
\hline & Baseline & 6 weeks & Baseline & 6 weeks & \\
\hline Hip circumference $(\mathrm{cm})$ & $110.28 \pm 1.11$ & $109.53 \pm 1.11$ & $114.33 \pm 7.03^{a}$ & $112.86 \pm 1.76^{\mathrm{b}}$ & $-0.72(-1.66 ; 0.23)$ \\
\hline Thigh circumference $(\mathrm{cm})$ & $62.13 \pm 0.84^{a}$ & $61.08 \pm 0.93^{b}$ & $63.82 \pm 1.20^{\mathrm{a}}$ & $62.45 \pm 1.03^{\mathrm{b}}$ & $-0.32(0.38 ;-1.07)$ \\
\hline Neck circumference $(\mathrm{cm})$ & $37.98 \pm 0.97^{\mathrm{a}}$ & $37.51 \pm 0.95^{\mathrm{b}}$ & $38.10 \pm 0.98^{\mathrm{a}}$ & $37.23 \pm 0.89^{\mathrm{b}}$ & $-0.24(-0.88 ; 0.07)$ \\
\hline Waist/hip index & $0.90 \pm 0.01^{\mathrm{a}}$ & $0.88 \pm 0.01^{\mathrm{b}}$ & $0.89 \pm 0.01^{\mathrm{a}}$ & $0.86 \pm 0.01^{b}$ & $-0.01(-0.02 ; 0.00)$ \\
\hline Conicity index & $1.29 \pm 0.02^{\mathrm{a}}$ & $1.26 \pm 0.02^{\mathrm{b}}$ & $1.30 \pm 0.02^{\mathrm{a}}$ & $1.26 \pm 0.01^{\mathrm{b}}$ & $-0.02(-0.04 ; 0.01)$ \\
\hline Total lean mass $(\mathrm{kg})^{1}$ & $49.13 \pm 3.10$ & $48.77 \pm 2.87$ & $48.11 \pm 3.07^{\mathrm{a}}$ & $49.14 \pm 3.12^{\mathrm{b}}$ & $0.03(-0.00 ; 0.06)$ \\
\hline Total body fat (kg) & $32.56 \pm 1.44^{\mathrm{a}}$ & $31.34 \pm 1.45^{\mathrm{b}}$ & $36.61 \pm 2.17^{\mathrm{a}}$ & $34.54 \pm 2.17^{\mathrm{b}}$ & $-0.85(-2.09 ; 0.37)$ \\
\hline Truncal fat mass $(\mathrm{kg})^{1}$ & $15.31 \pm 1.10$ & $14.82 \pm 1.01$ & $17.54 \pm 1.22^{\mathrm{a}}$ & $15.49 \pm 0.97^{b}$ & $-0.09(-0.18 ; 0.01)$ \\
\hline Android fat mass $(\mathrm{kg})^{1}$ & $2.21 \pm 0.21$ & $2.09 \pm 0.14$ & $2.54 \pm 0.17^{\mathrm{a}}$ & $2.17 \pm 0.12^{\mathrm{b}}$ & $-0.10(-0.22 ; 0.02)$ \\
\hline Bone mineral density $\left(\mathrm{g} / \mathrm{cm}^{2}\right)$ & $3.04 \pm 0.12$ & $3.03 \pm 0.14$ & $3.14 \pm 0.16$ & $3.13 \pm 0.16$ & $0.00(-0.11 ; 0.11)$ \\
\hline Systolic blood pressure (mmHg) & $113.96 \pm 2.93$ & $111.92 \pm 1.99$ & $112.66 \pm 2.33$ & $110.41 \pm 3.07$ & $-0.21(-6.95 ; 6.53)$ \\
\hline Diastolic blood pressure $(\mathrm{mmHg})^{1}$ & $69.30 \pm 2.09$ & $66.53 \pm 1.44$ & $67.33 \pm 1.98$ & $67.25 \pm 3.11$ & $0.04(-0.08 ; 1.6)$ \\
\hline
\end{tabular}

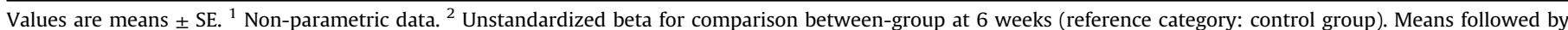
different lowercase letters, in the same line, indicate intra-group difference by generalized estimating equation model (GEE), $\mathrm{p}<0.05$. 

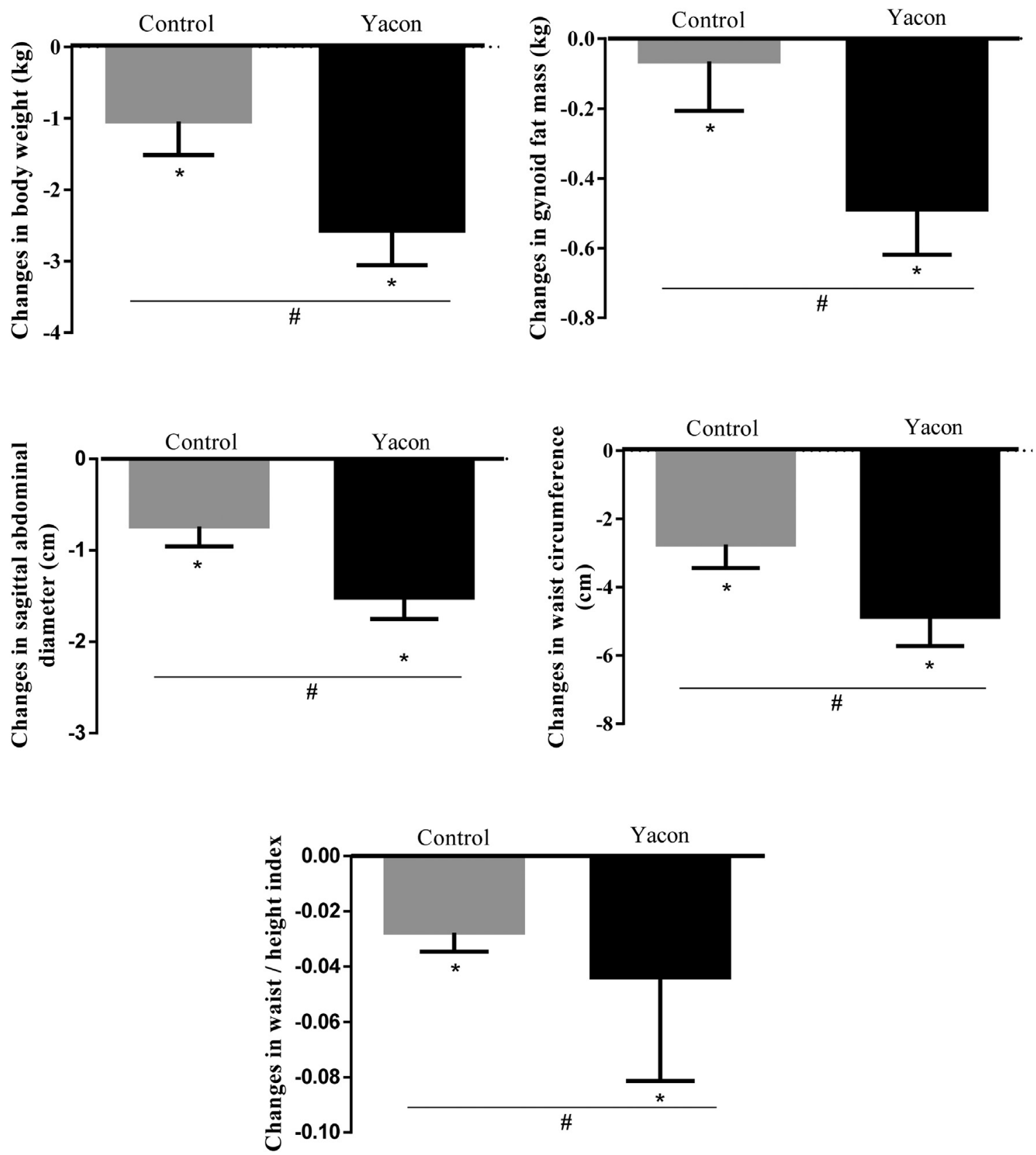

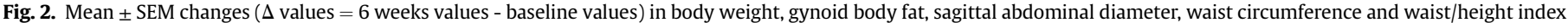

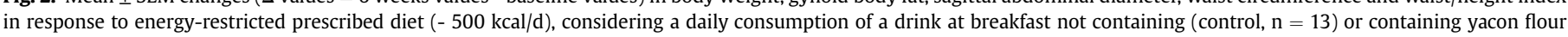

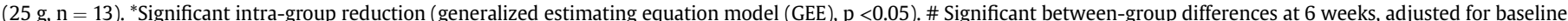
(GEE, p <0.05).

\section{Discussion}

Our results show that daily consumption of $25 \mathrm{~g}$ of yacon flour ( $0.1 \mathrm{~g}$ FOS $/ \mathrm{kg}$ body weight/day) was well tolerated and can be used as a nutritional strategy to aid in the control of excess body weight. Although about $15 \%$ of the subjects reported of abdominal discomfort symptoms such as flatulence and abdominal pain during the first days of intervention, these effect reduced after the second week and no significant difference in such symptoms was observed between groups at the end of the experiment. Like other non-digestible carbohydrates, FOS is fermented by the intestinal bacteria, leading to the production of gases such as carbon dioxide and hydrogen, which can result in gastrointestinal tract adverse effects. The severity of these effects appears to be dosedependent. Doses less than $0.29 \mathrm{~g}$ FOS/ $/ \mathrm{kg}$ body weight/day have been shown to be well tolerated, resulting in few adverse gastrointestinal effects [6,22].

In the present study, yacon flour supplementation (YAC group) resulted in a greater increase in fiber consumption, besides leading to lower body weight, gynoid body fat, waist circumference, waist/ height index and sagittal abdominal diameter than CON group. In addition, a reduction of body fat in specific regions (trunk and android) and an increase in total lean mass was observed only in the yacon flour supplemented group.

The greater weight loss and body composition changes in response to the consumption of yacon flour could be explained 
Table 6

Gastrointestinal function markers at baseline and after the 6-week intervention according to experimental groups.

\begin{tabular}{|c|c|c|c|c|c|}
\hline & \multicolumn{2}{|c|}{ Control $(n=13)$} & \multicolumn{2}{|c|}{ Yacon flour $(\mathrm{n}=13)$} & \multirow[t]{2}{*}{$\beta^{2}(95 \% \mathrm{CI})$} \\
\hline & Baseline & 6 weeks & Baseline & 6 weeks & \\
\hline Fecal pH & $7.23 \pm 0.11$ & $7.48 \pm 0.13$ & $7.16 \pm 0.14$ & $7.32 \pm 0.11$ & $-0.08(-0.47 ; 0.66)$ \\
\hline Bristol scale ${ }^{1}$ & $3.38 \pm 0.27$ & $3.30 \pm 0.25$ & $3.92 \pm 0.29$ & $4.30 \pm 0.25$ & $0.12(-0.06 ; 0.29)$ \\
\hline Abdominal pain ${ }^{1}$ & $1.31 \pm 0.22$ & $1.46 \pm 0.25$ & $1.46 \pm 0.23$ & $2.03 \pm 0.49$ & $0.44(-0.21 ; 1.09)$ \\
\hline Heartburn $^{1}$ & $1.07 \pm 0.07^{\mathrm{A}}$ & $1.23 \pm 0.16$ & $1.54 \pm 0.17^{\mathrm{B}}$ & $1.69 \pm 0.27$ & $-0.04(-0.53 ; 0.45)$ \\
\hline Reflux $^{1}$ & $1.00 \pm 0.00^{\mathrm{A}}$ & $1.15 \pm 0.14$ & $1.30 \pm 0.13^{B}$ & $1.15 \pm 0.10$ & $-0.27(-0.56 ; 0.03)$ \\
\hline Nausea $^{1}$ & $1.00 \pm 0.00$ & $1.23 \pm 0.16$ & $1.15 \pm 0.10$ & $1.15 \pm 0.14$ & $-0.21(-0.52 ; 0.11)$ \\
\hline Flatulence & $3.23 \pm 0.36$ & $3.00 \pm 0.39$ & $4.30 \pm 0.44$ & $3.84 \pm 0.44$ & $-0.23(-1.62 ; 1.16)$ \\
\hline Constipation $^{1}$ & $1.38 \pm 0.17$ & $1.92 \pm 0.36^{\mathrm{A}}$ & $1.92 \pm 0.44$ & $1.46 \pm 0.17^{\mathrm{B}}$ & $-0.60(-1.17 ;-0.02)$ \\
\hline Loose stools ${ }^{1}$ & $1.69 \pm 0.33$ & $1.46 \pm 0.30^{\mathrm{A}}$ & $1.69 \pm 0.22$ & $2.53 \pm 0.43^{\mathrm{B}}$ & $0.55(0.71 ; 1.03)$ \\
\hline Hard stools ${ }^{1}$ & $1.84 \pm 0.21$ & $1.77 \pm 0.29$ & $2.61 \pm 0.50^{\mathrm{a}}$ & $1.61 \pm 0.25^{\mathrm{b}}$ & $-0.44(-1.02 ; 0.14)$ \\
\hline Feeling of incomplete evacuation ${ }^{1}$ & $2.07 \pm 0.45$ & $2.30 \pm 0.49$ & $2.23 \pm 0.52$ & $2.38 \pm 0.46$ & $-0.04(-0.62 ; 0.55)$ \\
\hline
\end{tabular}

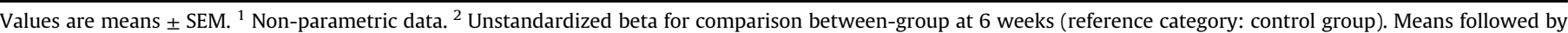

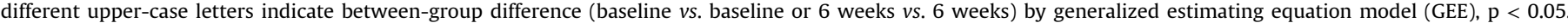

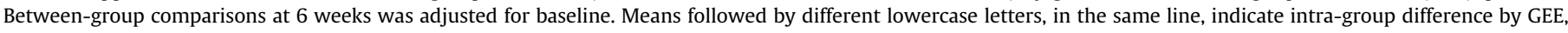
$\mathrm{p}<0.05$.

in part by the lower energy intake by the YAC group. Although not significant, energy intake reduction was $40 \%$ higher in the YAC compared to the CON group $(-460.9 \pm 463.8 \mathrm{kcal} v s .-324.9 \pm$ $567.3 \mathrm{kcal}$, respectively), although both groups received prescriptions of diets with the same energy restriction $(-500 \mathrm{kcal} / \mathrm{d})$. Dietary fiber supplementation, such as yacon flour, seems to attenuate food intake by various mechanisms [23,24]. The most widely reported mechanism is related to FOS regulation of endogenous intestinal peptides production. FOS appears to increase peptide YY concentration, while suppressing ghrelin and leptin secretions [24], thus reducing appetite and food intake.

FOS may also increase the activity of adenosinemonophosphate-activated-protein-kinase (AMPK) in muscle and liver tissue $[25,26]$. That enzyme increases energy and fatty acid metabolism by a mechanism associated with the peroxisomeproliferator-activated-receptor- $1 \alpha$-coactivator (PGC-1 $\alpha$ ) [26]. Thus, that effect may have contributed to greater reductions of body weight, sagittal abdominal diameter and body fat in certain regions of the body in the YAC group.

The results of the present study suggest that yacon may be an adjuvant in intestinal constipation treatments. Subjects who consumed yacon flour had a lower stool consistency and constipation frequency compare with subjects in the control group. The occurrence of intestinal constipation is common in overweight individuals [27], and it is positively related to increased colon cancer risk [28]. That condition may affect intestinal microbiota, decreasing the number of beneficial bacteria (eg bifidobacteria) and increasing the number of potentially pathogenic microorganisms and fungi. FOS fermentation produces short chain fatty acids (propionate, butyrate and acetate), resulting in a decrease in the colon $\mathrm{pH}$, which in turn affects the microbiota composition. Under low $\mathrm{pH}$ conditions the growth of pH-sensitive pathogenic bacteria, such as Enterobacteria and Clostridia, is suppressed while there is an increase of Bibidobacterium and Lactobacillus [22]. Acidification also favors water retention in the intestinal lumen as a way to preserve the osmotic pressure, promoting an increase in stools viscosity and humidity, besides reducing intestinal constipation [29].

Similar results to the ones verified in the present study have been observed with yacon consumption. In a study involving lightly dyslipidemic obese premenopausal women, consumption of yacon syrup ( $0.14 \mathrm{~g}$ FOS/kg body weight/day) for 120 days increased satiety, reduced body weight and waist circumference, in addition to increasing the evacuation frequency [6]. The addition of a yaconbased product (10 g FOS/day, approximately $0.15 \mathrm{~g}$ FOS/kg body weight) to orange juice for 30 days also increased evacuations, improved stools consistence and reduced constipation score in constipated adults/elderly individuals [22]. In another study, the consumption of yacon syrup (20 g/day, containing $6.4 \mathrm{~g}$ FOS) significantly reduced intestinal transit time in healthy subjects [9].

Consumption of $25 \mathrm{~g}$ of yacon flour did not affect most of the concentration of the biochemical variables evaluated in this study. However, all dyslipidemic subjects had an improvement in the lipid profile at the end of the study compared to baseline, and in half of them, the values reached normality. It should be noted however, that except of the lipid profile, our subjects had all the other biochemical variables assessed were within normal ranges. Thus, we believe that yacon flour may exert its beneficial effects only in metabolically decompensated individuals. Data from an animal study corroborate with our hypothesis. Diabetic and healthy animals (control) received $1.06 \mathrm{~g}$ yacon root extract $/ \mathrm{kg}$ body weight/ day (equivalent to $0.34 \mathrm{~g}$ of FOS/ $\mathrm{kg}$ body weight/day) for 14 days. Although diabetic animals had glycemia $170 \%$ higher at baseline compared to controls, yacon supplementation brought it to near to normal values. However, no change in glucose concentrations was observed in control mice [30].

In subjects with reduced glucose tolerance [8], insulin-resistant and dyslipidemic [6] and in subjects with diabetes [7], yacon supplementation in lyophilized form ( $0.1 \mathrm{~g}$ FOS/ $\mathrm{kg}$ body weight/day for 9 weeks), in extract ( $3 \mathrm{~g}$ extract/day for 90 days, concentration of FOS was not available) or syrup (0.14 g FOS $/ \mathrm{kg}$ body weight), significantly reduced the concentrations of variables associated with glucose metabolism (glycemia, insulin, and HOMA-IR) and lipid profile (LDL-c). In a previous study conducted by our group [4], glycemic response was not affected in response to yacon flour consumption ( $0.13 \mathrm{~g}$ FOS/ $/ \mathrm{kg}$ body weight/day) in healthy euglycemic individuals.

The results of the present study suggest that yacon flour can be used as a dietary fiber supplement and that the consumption of $25 \mathrm{~g} /$ day by adult subjects ( $0.1 \mathrm{~g}$ FOS/kg body weight/day) appears to be an interesting strategy to help control excess body weight. In addition to being well tolerated, that supplementation increased fiber consumption, improved bowel function. It also increased body weight, body fat, waist circumference, waist/height ratio and sagittal abdominal diameter reduction, besides increasing total lean mass.

Our study has several strengths. First, we evaluated a food source of FOS, rather than a synthetic source. In addition, we chose to test yacon flour because it presented greater FOS content stability than yacon root. Second, our study was double-blind and double-typed data. In addition, we used strict eligibility criteria, we used DXA to evaluate body composition, and breakfast was consumed in the laboratory to guarantee adherence to the protocol. 
Finally, our study differed from most studies already published for having included men and women in the sample. On the other hand, overweight individuals tend to underestimate the amount of food consumed. Thus, the use of the food records to assess food intake was a limitation. Despite of that, food records are widely used by other authors, since it is easy to apply and allow subjects to remain in free living conditions.

In summary, daily consumption of $25 \mathrm{~g}$ of yacon flour ( $0.1 \mathrm{~g}$ FOS/ $\mathrm{kg}$ body weight/day) for 6 weeks by overweight subjects was well tolerated and allowed dietary fiber intake to become adequate, resulted in lower constipation frequency and improved stools consistency, besides leading to lower body weight, body fat, waist circumference, waist-to-weight ratio and sagittal abdominal diameter than the CON group. In addition, it did not negatively affect the concentrations of the biochemical variables assessed. Thus, yacon flour seems to be a suitable nutritional strategy to be used in association with energy restriction diets to control excess body weight.

\section{Funding}

This project is funded and supported by Fundação de Amparo à Pesquisa do Estado de Minas Gerais (FAPEMIG) (protocol number: APQ-02277-14).

\section{Statement of authorship}

All authors have made substantial contributions to the following areas of this manuscript. All authors designed the study. AMM and NBMS carried out the data collection and analyses. AMM completed the data and statistical analyses and drafted the manuscript. All authors edited, read and approved the final manuscript.

\section{Conflict of interest}

\section{The authors declare no conflict of interest.}

\section{Acknowledgements}

We thank Fundação de Amparo à Pesquisa do Estado de Minas Gerais (FAPEMIG), the Coordenação de Aperfeiçoamento de Pessoal de Nível Superior (CAPES) and Conselho Nacional de Desenvolvimento Científico e Tecnológico (CNPq) for providing research grants to the authors. We thank Bioclin ${ }^{\circledR}$ for providing biochemical assays kits. We thank Piracanjuba ${ }^{\circledR}$ and Tial ${ }^{\circledR}$ for providing milk and juice for the breakfast and dinner to participants. These companies had no role in design, analysis, or writing of this manuscript.

\section{Appendix A. Supplementary data}

Supplementary data to this article can be found online at https://doi.org/10.1016/j.clnesp.2018.12.082.

\section{References}

[1] World Health Organization. Obesity and overweight. 2018. http://www.who int/news-room/fact-sheets/detail/obesity-and-overweight. [Accessed 19 July 2018].

[2] Caetano BFR, de Moura NA, Almeida APS, Dias MC, Sivieri K, Barbisan LF. Yacon (Smallanthus sonchifolius) as a food supplement: health-promoting benefits of fructooligosaccharides. Nutrients 2016. https://doi.org/10.3390/nu8070436.

[3] Campos D, Aguilar-Galvez A, Pedreschi R. Stability of fructooligosaccharides, sugars and colour of yacon (Smallanthus sonchifolius) roots during blanching and drying. Int J Food Sci Technol 2016;51:1177-85.
[4] Rocha DMUP, Ribeiro PV de M, Caldas APS, da Silva BP, da Silva A, de Almeida AP, et al. Acute consumption of yacon shake did not affect glycemic response in euglycemic, normal weight, healthy adults. J Funct Foods 2018;44: 58-64.

[5] das G Vaz-Tostes M, Viana ML, Grancieri M, dos S Luz TC, de Paula H, Pedrosa RG, et al. Yacon effects in immune response and nutritional status of iron and zinc in preschool children. Nutrition 2014;30:666-72.

[6] Genta S, Cabrera W, Habib N, Pons J, Carillo IM, Grau A, et al. Yacon syrup: beneficial effects on obesity and insulin resistance in humans. Clin Nutr 2009;28:182-7.

[7] Gordillo G c, Negrón LP, Zúñiga TH, Flores E, Moreyra R, Fuertes C, et al. Efecto hipoglicemiante del extracto acuoso de las hojas de Smallanthus sonchifolius (Yacón) en pacientes con diabetes mellitus tipo 2. Cienc Invest 2012;15:42-7.

[8] Scheid MMA, Genaro PS, Moreno YMF, Pastore GM. Freeze-dried powdered yacon: effects of FOS on serum glucose, lipids and intestinal transit in the elderly. Eur J Nutr 2014:53:1457-64.

[9] Geyer M, Manrique I, Degen L, Beglinger C. Effect of yacon (Smallanthus sonchifolius) on colonic transit time in healthy volunteers. Digestion 2008;78: $30-3$.

[10] Campos D, Betalleluz-Pallardel I, Chirinos R, Aguilar-Galvez A, Noratto G, Pedreschi R. Prebiotic effects of yacon (Smallanthus sonchifolius Poepp. \& Endl), a source of fructooligosaccharides and phenolic compounds with antioxidant activity. Food Chem 2012;135:1592-9.

[11] Horwitz W. Official methods of analysis of AOAC International. Gaithersburg: AOAC International.; 2002.

[12] Pedreschi R, Campos D, Noratto G, Chirinos R, Cisneros-Zevallos L. Andean yacon root (Smallanthus sonchifolius Poepp. Endl) fructooligosaccharides as a potential novel source of prebiotics. J Agric Food Chem 2003;51:5278-84.

[13] Prosky L, Hoebregs H. Methods to determine food inulin and oligofructose. J Nutr 1999:129:1418S-23S.

[14] Associação Brasileira para Estudo da Obesidade e da Síndrome Metabólica. In: Diretrizes brasileiras de Obesidade. 4ed.4; 2016. p. 1-188.

[15] Mancia G, De Backer G, Dominiczak A, Cifkova R, Fagard R, Germano G, et al. Guidelines for the management of arterial hypertension: the task force for the management of arterial hypertension of the European society of hypertension (ESH) and of the European society of Cardiology (ESC). Eur Heart J 2007;28: $1462-536$.

[16] Martinez AP, Azevedo GR de. The Bristol Stool Form Scale: its translation to Portuguese, cultural adaptation and validation. Rev Lat Am Enfermagem 2012;20:583-9.

[17] Souza GS, Sardá FAH, Giuntini EB, Gumbrevicius I, Morais MB de, Menezes EW de. Translation and validation of the Brazilian Portuguese version of the gastrointestinal symptom rating scale (Gsrs) Questionnaire. Arq Gastroenterol 2016;53:146-51.

[18] Geloneze B, Tambascia MA. Avaliação laboratorial e diagnóstico da resistência insulínica. Arq Bras Endocrinol Metabol 2006. https://doi.org/10.1590/S000427302006000200007.

[19] Dobiásová M. AIP-atherogenic index of plasma as a significant predictor of cardiovascular risk: from research to practice. Vnitr Lek 2006;52:64-71.

[20] Mera R, Thompson H, Prasad C. How to calculate sample size for an experiment: a case-based description. Nutr Neurosci 1998;1:87-91.

[21] Flaudi A, Izar M, Saraiva J, Chacra A, Bianco H, Afiune Neto A, et al. Atualização da diretriz brasileira de dislipidemias e prevenção da aterosclerose-2017. 2017.

[22] Sant'Anna M de SL, Rodrigues VC, Araújo TF, de Oliveira TT, do Carmo Gouveia Peluzio M, de Luces Fortes Ferreira CL. Yacon-based product in the modulation of intestinal constipation. J Med Food 2015;18:980-6.

[23] Daud NM, Ismail NA, Thomas EL, Fitzpatrick JA, Bell JD, Swann JR, et al. The impact of oligofructose on stimulation of gut hormones, appetite regulation and adiposity. Obesity 2014;22:1430-8.

[24] Parnell JA, Reimer RA. Weight loss during oligofructose supplemen- tation is associated with decreased ghrelin and increased peptide YY in overweight and obese adults. Am J Clin Nutr 2009;89:1751-9.

[25] den Besten G, van Eunen K, Groen AK, Venema K, Reijngoud D-J, Bakker BM. The role of short-chain fatty acids in the interplay between diet, gut microbiota, and host energy metabolism. J Lipid Res 2013;54:2325-40.

[26] Gao Z, Yin J, Zhang J, Ward RE, Martin RJ, Lefevre M, et al. Butyrate improves insulin sensitivity and increases energy expenditure in mice. Diabetes 2009:58:1509-17.

[27] Pourhoseingholi MA, Kaboli SA, Pourhoseingholi A, Moghimi-Dehkordi B, Safaee A, Mansoori BK, et al. Obesity and functional constipation; a community-based study in Iran. J Gastrointestin Liver Dis 2009;18:151-5.

[28] Roberts MC, Millikan RC, Galanko JA, Martin C, Sandler RS. Constipation, laxative use, and colon cancer in a North Carolina population. Am J Gastroenterol 2003;98:857-64.

[29] Oku T, Nakamura S. Fructooligosaccharide: metabolism through gut microbiota and prebiotic effect. Food Nutr J 2017;2017:128.

[30] Biazon ACB, Wendt MMN, Ghizoniet CVC, Soares AA, Silveira SS, et al. The in vitro antioxidant capacities of hydroalcoholic extracts from roots and leaves of Smallanthus sonchifolius ( yacon ) do not correlate with their in vivo antioxidant action in diabetic rats. Sci Res Publ 2016;4:13. 